\title{
INTERACTION OF HEATED HIGH PURITY METALS WITH METASTABLE OXYGEN
}

\author{
J. LAMARRE, J. BONNET and D. PIGACHE \\ Office National d' Etudes et de Recherches Aérospatiales, BP. 72, F-92322 Châtillon cedex, France
}

\begin{abstract}
Visible emission is observed when metastable oxygen $0_{2}\left({ }^{1} \Delta g\right)$ produced in a microwave discharge interacts with various heated high purity metal wires containing few ppm of copper. Spectra in the visible and the near infrared are presented. The visible spectra are identical with those obtained in subsequent copper wire experiments. These results tend to prove that $\mathrm{CuCl}_{2}$ is not the visible emitter.
\end{abstract}

\section{1 - Introduction.}

Yoshida et al ${ }^{(1)}$ have reported on a new intense visible emission that occurs when $\mathrm{O}_{2}\left({ }^{1} \Delta \mathrm{g}\right)$ flows over heated copper. The same visible chemiluminescence was observed by several groups $[2,3,4]$ with other metals such as aluminum, silver, platinum. An infrared emission is also observed with copper and other metals but it depends on the nature of the metal (2). Most recently, Tokuda et al [5] have proposed that the visible and infrared emitters are excited states of $\mathrm{CuCl}_{2}$. They have also suggested that pollution by copper could explain the emissions with other metals. A recent spectral analysis made by A.J. Bouvier et al [6] tends to confirm that $\mathrm{CuCl}_{2}$ is responsible for both emissions. In the present paper, we report on the spectra obtained. with different high purity metal wires in the visible and the infrared. Arguments are also given whom suggest that $\mathrm{CuCl}_{2}$ is not the visible emitter even with copper.

\section{2 - Experiment}

In our experiment (figure 1) the metastable oxygen $0_{2}\left({ }^{1} \Delta g\right.$ ) is generated by means of a microwave discharge in oxygen. A Hgo ring traps the residual oxygen atoms produced in the discharge. Chlorine is injected in the $0_{2}\left({ }^{1} \Delta g\right)$ flow. A high purity metal wire coil has been placed in our test cell. The resistively heated coil is held by two high purity nickel rods without solder. In a first series of experiments, only three metal wires have been tried: aluminum, platinum, silver with a maximum copper concentration of $5 \mathrm{ppm}$ as stated by the manufacturer. Our experimental device had not been polluted by previous experiments with copper. In a -econd series of experiments, a copper wire has been tried in order to compare 
directly the different spectra. The emitted spectra are recorded in two ways: an optical multichannel analyser for the visible range and a grating monochromator with a cooled germanium detector for the infrared.

\section{3 - Results and discussion}

A visible emission has been observed with aluminum, platinum and silver but it does not last as long as in the case of copper. As shown in figures 2 and 3 , the visible emission spectra are almost the same with copper, aluminum, platinum or silver. They all exhibit two typical intervals of about $360 \mathrm{~cm}^{-1}$ and $25 \mathrm{~cm}^{-1}$ between the peaks corresponding to different vibrational structures. In comparison with copper, the visible emission is weaker by a factor of about 40 in the case of $\mathrm{Al}$ and $\mathrm{Ag}$ whereas in the case of $\mathrm{Pt}$, it is weaker by a factor of about 20 . Attempts have been made to observe the infrared emission undoubtedly assigned to $\mathrm{CuCl}_{2}$ [6] with $\mathrm{Al}$ and $\mathrm{Pt}$ between 1100-1500 nm. Figure 4 gives the infrared spectra for copper and platinum. The two spectra are different. For platinum, the $0_{2}\left({ }^{1} \Delta g\right)$ emission at $1270 \mathrm{~nm}$ is well observed superposed on a continuum. Whereas in the case of copper, the $\mathrm{CuCl}_{2}$ emission is two decades stronger than the $\mathrm{O}_{2}\left({ }^{1} \Delta g\right)$ emission.

\section{4 - Conclusion}

As in our experiment, the minute traces of copper contained in the different metals do not induce the infrared $\mathrm{CuCl}_{2}$ emission, they are probably not responsible of the visible emission; so it seems that $\mathrm{CuCl}_{2}$ cannot be the visible emitter even in the case of experiments with pure copper. This is obviously in contradiction with the conclusion of ${ }^{(6)}$. We currently improve our detection system in order to obtain better infrared spectra in a wider energy range. This weak infrared emission obtained with platinum is presently unknown and the real nature of the visible emitter remain an open question.

\section{References}

[1] YOSHIDA, S., SHIMIZU, K., SAWANO, T., TOKUDA, T., and FUJIOKA, T., Appl. Phys. Lett., $\underline{54}$ (1989) 2400.

[2] BACIS, R., BONNET, J., BOUVIER, A.J., CROZET, P., CHURASSY, S., GEORGES, E., ERBA, B., LAMARRE, J., LOUVET, Y., NOTA, M., PIGACHE, D., ROSS, A.J., and SETRA, M., Europhys. Lett., 12, (1990), 569.

[3] ZHANG, Q., CUI, T.J., XIE, X.B., SANG, F.T., YUAN, Q.N., ZHANG, R.Y., YANG, H.P., LI, L., ZHU, Q.S., and ZHANG, C.H., Conf. Proc. CLEO/IQEC, Anaheim, May 21-25, 1990, California.

[4] HUANG, R., ZHANG, R. and ZARE, R.N., Chem. Phys. Lett., 170 (1990), 437.

[5] TOKUDA, T., FUJII, N., YOSHIDA, S., SHIMIZU, K., and TANAKA, I., Chem. Phys. Lett., $174(1990), 385$. 
[6] BOUVIER, A.J., BACIS, R., BONNET, J., CHURASSY, S., CROZET, P., ERBA, B., KOFFEND, J.B., LAMARRE, J., LAMRINI, M., PIGACHE, D., and ROSS, A.J, Conf. Laser M2P, Grenoble July 9-11, 1991.

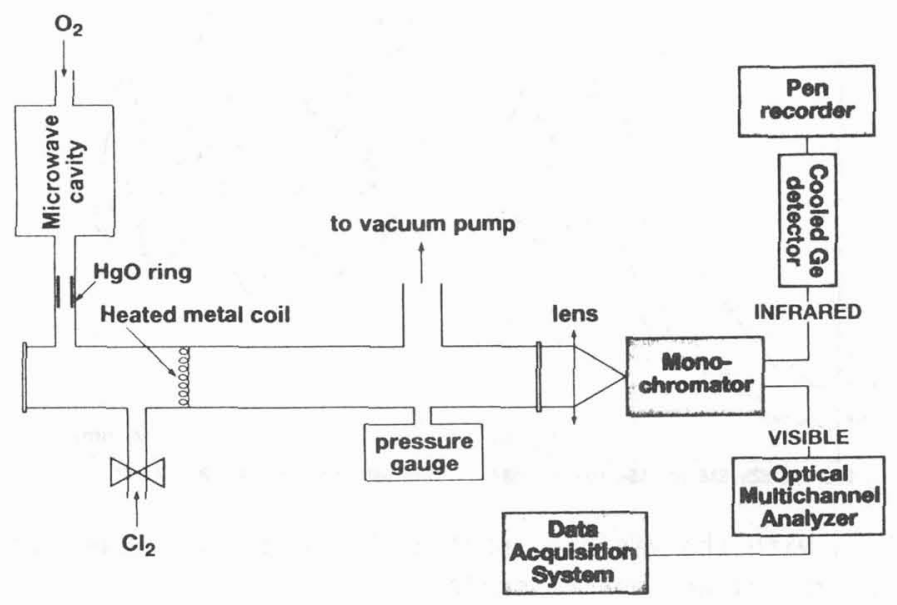

Fig. 1 - Experimental device.

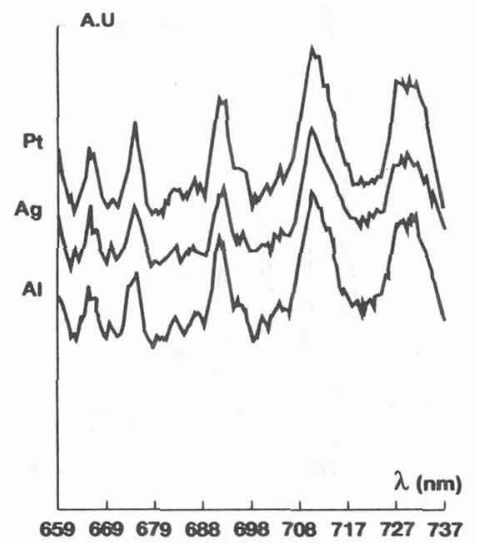

Fig. 2 - Fluorescence spectra of the red emission obtained with differents metal wires. The amplitudes values are not to scale. 

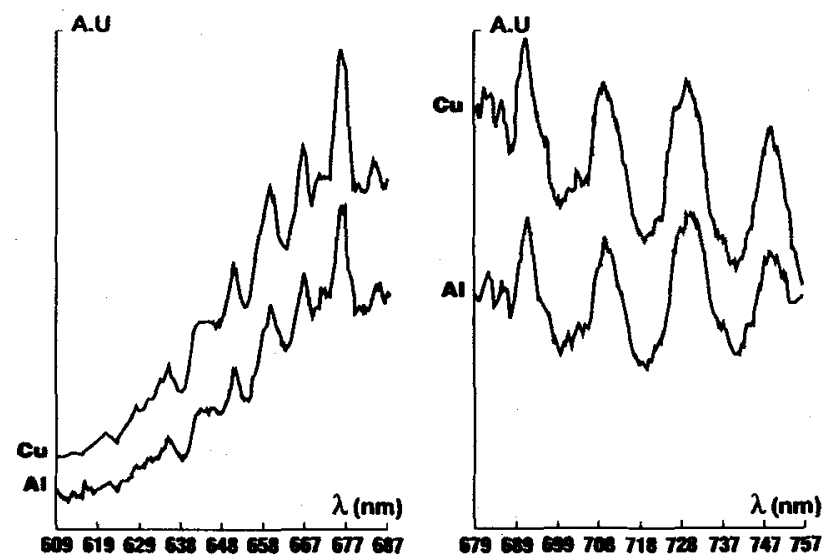

Fig. 3 - Comparison with the visible spectra obtained with copper and aluminum. The amplitude values are not to scale.

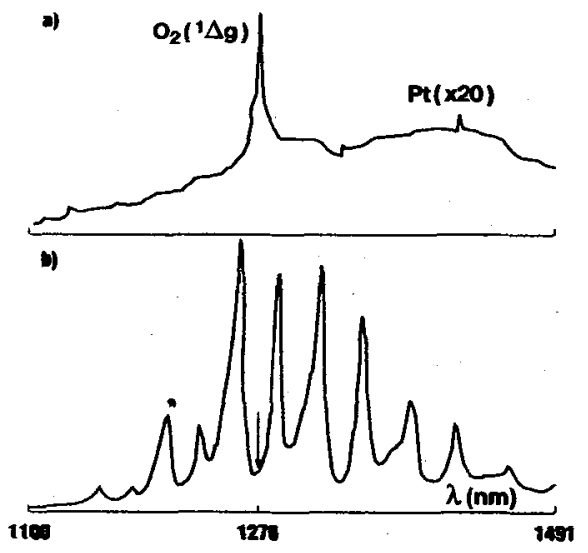

Fig. 4 - Emission infrared spectra.

a) platinum.

b) copper 